\title{
Development and characterization of EST-SSRs for Muscidae (Diptera) and their cross-genera transferability
}

\author{
Dan-Dan Wang \& Dong-Xia Yang
}

Wang, D.-D. \& Yang, D.-X. 2017: Development and characterization of ESTSSRs for Muscidae (Diptera) and their cross-genera transferability. - Entomologica Fennica 28: 148-156.

EST-SSR (Expressed Sequence Tag-Simple Sequence Repeat) markers were developed and used to examine genetic diversity of species assemblages of ten genera of Muscidae (Diptera), and specifically the genetic diversity of Phaonia Robineau species, from ten regions in China. 18 EST-SSR markers with high polymorphism and clear bands were screened out from 216 tested markers, with 219 alleles in total (95-280 bp) with an average of 6.1 alleles per locus. In various regions in China such as Tibet, Sichuan, and Yunnan, Muscidae species assemblages exhibited rich genetic diversity, with the polymorphism information content (PIC) values ranging from 0.831 to 0.934 , while Hainan region showed a relatively low genetic diversity $(\mathrm{PIC}=0.511)$. Low gene flow $\left(\mathrm{N}_{\mathrm{m}}=0.842\right)$ was found among the regions, and the average genetic differentiation coefficient $\left(\mathrm{F}_{\mathrm{st}}\right)$ was 0.238 , indicating a high degree of genetic differentiation among the ten surveyed assemblages. Accordingly, the ten genera of Muscidae exhibited high genetic diversity and genetic differentiation.

D.-D. Wang \& D.-X. Yang, Agricultural College, Eastern Liaoning University, Dandong 118000, P. R. China; corresponding author's e-mail: wangdandansq (a)sina.com

Received 2 August 2016, accepted 30 March 2017

\section{Introduction}

Muscidae is one of the four families of the muscoid grade of Calyptratae (Diptera: Cyclorrhapha). The family is mainly distributed in the Palaearctic (Hennig 1955-1964) and Nearctic regions (Carvalho et al. 2002), with some species occurring in the Oriental region. Muscidae flies are often very abundant (McAlpine 1981) and some species can be found in urban environments as pest species, being carriers of pathogenic bacteria and thus potentially spreading diseases. However, the vast majority of Muscidae live in natural areas, e.g. mountains, being sapropha- gous in decaying organic matter, or ingesting dew or flower nectar (Michelsen 2000).

Because the morphology of the flies in Muscidae is often very similar (e.g. Xue et al. 1992), it is frequently difficult to identify the fly species according to their morphological characteristics. Although there are many species whose morphological identification is uncomplicated, the number of variable morphological characteristics is numerous, and some characters are strongly influenced by environmental factors, which could lead to erroneous identification of species (Evenhuis et al. 2010). However, identification based on molecular markers, especially the DNA 
Table 1. Regions (China) and sample sizes of the ten genera of Muscidae used in the study.

\begin{tabular}{|c|c|c|c|c|c|c|c|c|c|c|}
\hline & XT & $\mathrm{XN}$ & QK & YY & SE & HW & ST & $\mathrm{NC}$ & LQ & $\mathrm{JC}$ \\
\hline Fannia & 8 & & 11 & & 23 & & 10 & & & \\
\hline Hydrotaea & & & & & & & 6 & 13 & & 16 \\
\hline Drymeia & & 6 & 5 & 8 & 6 & & & & & \\
\hline Myospila & 2 & & & & 7 & 8 & 11 & & 10 & \\
\hline Spilogona & & & 9 & 7 & & & 8 & & & 10 \\
\hline Brontaea & 7 & & & 8 & & 6 & & & 6 & 11 \\
\hline Lispe & 6 & 6 & & 4 & & 7 & 9 & & 10 & \\
\hline Coenosia & & & & & 5 & & & 7 & 6 & \\
\hline Helina & 4 & 6 & 11 & & 5 & & & & & 13 \\
\hline Phaonia & 2 & 8 & 4 & 10 & 11 & 7 & 5 & 9 & 7 & 9 \\
\hline
\end{tabular}

XT: Tian-Mountain of Xinjiang, $43^{\circ} 8^{\prime} 20^{\prime \prime} \mathrm{N} 88^{\circ} 3^{\prime} 17^{\prime \prime} \mathrm{E}, 5,445 \mathrm{~m}$ a.s.I.

$\mathrm{XN}$ : Nianqingtanggula-Mountain of Xizang, $30^{\circ} 4^{\prime} 2^{\prime \prime} \mathrm{N} 90^{\circ} 6^{\prime} 2^{\prime \prime} \mathrm{E}, 7,117 \mathrm{~m}$ a.s.l.

QK: Kunlun-Mountain of Qinhai, $34^{\circ} 47^{\prime} 23^{\prime \prime} \mathrm{N} 99^{\circ} 27^{\prime} 18^{\prime \prime} \mathrm{E}, 6,282 \mathrm{~m}$ a.s.I.

YY: Yulongxue-Mountain of Yunnan, $27^{\circ} 3^{\prime} 2$ 'N $100^{\circ} 4^{\prime} 2 " \mathrm{E}, 5,596 \mathrm{~m}$ a.s.I.

SE: Emei-Mountain of Sichuan, 30'16'30"N 103'10'30"E, 3,099 m a.s.I.

HW: Wuzhi-Mountain of Hainan, $18^{\circ} 48^{\prime} 59^{\prime \prime} \mathrm{N} 109^{\circ} 32^{\prime} 03^{\prime \prime} \mathrm{E}, 1,867 \mathrm{~m}$ a.s.I.

ST: Taihang-Mountain of Shanxi, $34^{\circ} 34^{\prime} 16^{\prime \prime} \mathrm{N} 110^{\circ} 14^{\prime} 08^{\prime \prime} \mathrm{E}, 2,882 \mathrm{~m}$ a.s.l.

NC: Chifeng Neimenggu, $41^{\circ} 17^{\prime} 10^{\prime \prime} \mathrm{N} 116^{\circ} 21^{\prime} 07^{\prime \prime} \mathrm{E}, 2,067 \mathrm{~m}$ a.s.I.

LQ: Qian-Mountain of Liaoning, $40^{\circ} 55^{\prime} 30^{\prime \prime} \mathrm{N} 122^{\circ} 49^{\prime} 2$ "E, $708 \mathrm{~m}$ a.s.I.

JC: Changbai-Mountain of Jinlin, $41^{\circ} 41^{\prime} 49^{\prime \prime} \mathrm{N} 127^{\circ} 42^{\prime} 55^{\prime \prime} \mathrm{E}, 2,691 \mathrm{~m}$ a.s.I.

fingerprinting technologies, are accurate, repeatable, simple and fast to perform (Posada 2008). The EST-SSR (Expressed Sequence Tag-Simple Sequence Repeats) molecular markers are a relatively new group of DNA-based genetic markers (Schuehli et al. 2007). In comparison with morphological characteristics, cytological or biochemical markers, the EST-SSR markers are faster, better and more economical for testing and use in research. The EST-SSR markers take the form of coding DNA sequence, which can be detected in various tissues and various stages of growth or development of e.g. flies. Furthermore, the EST-SSR markers are not subjected to seasonal, environmental or human influenced (subjective) factors (Savage \& Wheeler 2004). The enormous numbers of EST-SSR markers cover the entire genome, they are characterized as highly polymorphic, co-dominant and reliable markers, which make it possible to identify homozygous and heterozygous genotypes. In basing on expressed sequence tags, EST-SSRs produce simple sequence repeats, in comparison to the genome SSR (also called microsatellites), and the advantage of the former is their high transferability across species.

Currently, EST-SSR markers are widely used for genomics research, such as genetic mapping, comparative mapping, and analysis of the genetic diversity, germplasm identification, phylogenetics and evolution.

EST-SSRs are generated by sequencing cDNA, which itself is synthesized from the mRNA molecules in cells and are thus copies of the genes that are being expressed (Renaud et al. 2012). mRNA does not contain sequences from the regions between the genes, nor from the noncoding introns that are present within many parts of the genome that are useful in practical research. The expressed genes constitute $3-5 \%$ of the whole genome, so a $300-400 \mathrm{bp}$ EST is enough to reflect the gene characteristics.

To date, very few reports exist about genetic diversity of Muscidae species. In this study, ESTSSR primers were developed for Muscidae taxa, which could be useful for generating e.g. DNA fingerprints for identification of Muscidae species. Here EST-SSR markers were used to examine the genetic diversity of ten genera of Muscidae and of Phaonia species from ten regions in natural populations in China.

\section{Materials and methods}

\subsection{Fly materials}

The research objects of this study were the flies in 10 representative genera of Muscidae from 10 


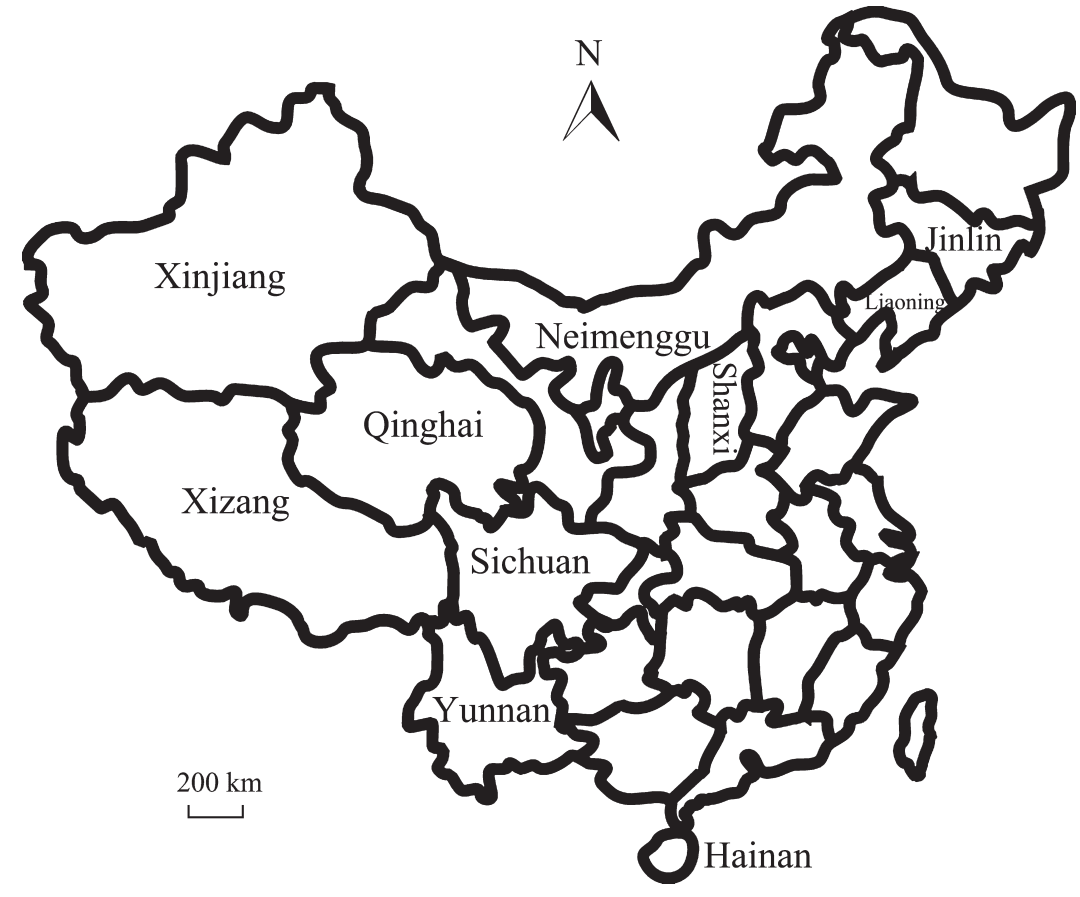

Fig. 1. Map of China showing the ten regions where samples of Muscidae were collected. provinces in China (Table 1, Fig. 1). All fly samples were collected during more than 8 years. The fly material is preserved in the museum of the Agricultural college of Eastern Liaoning University and Institute of Entomology, Shenyang Normal University.

\subsection{DNA extraction and amplification}

The flies were crushed with a mortar and pestle, the tissue homogenate was put into an eppendorf tube which had $40 \mu 10.25 \mathrm{~mol} \cdot \mathrm{L}^{-1} \mathrm{NaOH}$, held 30 $\mathrm{s}$ in boiling water; then $40 \mu 10.25 \mathrm{~mol} \cdot \mathrm{L}^{-1} \mathrm{HCl}$ and $20 \mu 10.5 \mathrm{~mol} \cdot \mathrm{L}^{-1}$ Tris- $\mathrm{HCl}(\mathrm{pH} 8.0$, containing $0.25 \%$ Nonidet-P-40) was added, held 2 min in boiling water, then the tissue homogenate was used in $25 \mu 1$ PCR reactions. PCR reactions: 2.5 $\mu 110 \times$ reaction buffer, $2 \mu 12.5 \mathrm{mmol} \cdot \mathrm{L}^{-1}$ of each dNTPs, $1 \mathrm{U}$ of Taq polymerase, $0.5 \mu 110 \mu \mathrm{mol}$. $\mathrm{L}^{-1}$ each of forward and reverse primers, 50-100 ng tissue homogenate, $1.5 \mu 1 \quad 1.5 \mathrm{mmolL}^{-1}$ $\mathrm{MgCl} 2$, then added double-distilled water up to total $25 \mu 1$ reaction volume (Kutty et al. 2008). The following PCR program was used: the initial hot-start of a denaturation step at $94{ }^{\circ} \mathrm{C}$ for 10 min, followed by 35 cycles of a $50 \mathrm{~s}$ denaturation step at $94{ }^{\circ} \mathrm{C}$, a $50 \mathrm{~s}$ annealing step at $58-60{ }^{\circ} \mathrm{C}$, and a 1 min extension step at $72^{\circ} \mathrm{C}$, and the final extension step at $72^{\circ} \mathrm{C}$ for $10 \mathrm{~min}$ before holding the sample at $4{ }^{\circ} \mathrm{C}$.

\subsection{EST-SSR primers}

All the available Muscidae EST sequences up to January 2016 were downloaded from GenBank/ NCBI EST database (National Center for Biotechnology Information http://www.ncbi.nlm. nih.gov). For developing EST-SSR primers, the steps were as follows. Using Perl software (www.perl.org) all 21,880 Muscidae EST sequences were assembled in FASTA format. The Blastclust software (www.ncbi.nlm.nih.gov) was used in searching for the redundant sequences in all EST sequences. Then, using the CD-HIT software (http://weizhongli-lab.org/cd-hit/), the short $(<100 \mathrm{bp})$ and long sequences $(>700 \mathrm{bp})$ were removed, as also the 5'-hat and 3'-poly tail (A or T) of mRNA by EST-TRIMMER software. The MISA.PL software was used to search, identify and locate SSR sites, and primer 3 was used to develop EST-SSR primers. The designed parameters of the EST-SSR primers were as follows: 
length $20-25 \mathrm{bp}$, annealing temperature $\left(\mathrm{T}_{\mathrm{m}}\right) 56$ $63{ }^{\circ} \mathrm{C}$, and the content of $\mathrm{G}+\mathrm{C}$ was $30-70 \%$. Finally, BLAST was used to test these developed primers.

\subsection{EST-SSR primers screening}

The developed EST-SSR primers were used to PCR amplified 46 DNA samples of different Muscidae genera (Chen 2009). The amplified fragments were separated and analyzed using $6 \%$ polyacrylamide gel electrophoresis for $1.5 \mathrm{~h}$ (constant power $55 \mathrm{~W}$, DNA marker GsDL0501 from $50 \mathrm{bp}$ to $500 \mathrm{bp}$ ). The primers were tested and screened three times, and then, of the screened primers those, which amplified stable, polymorphic and clear bands, were chosen in the final study.

\subsection{Data analysis}

The different amplified bands (EST-SSR products) that were generated by each primer pair were identified using gel electrophoresis. The EST-SSR molecular markers were recorded in co-dominant format, and therefore they can identify the homozygous and heterozygous genotype. POPGENE version 1.32 was used to analyze the genetic diversity of each polymorphic locus, including expected heterozygosity $\left(\mathrm{H}_{\mathrm{e}}\right)$, observed heterozygosity $\left(\mathrm{H}_{\mathrm{o}}\right)$, coefficient of genetic differentiation $\left(\mathrm{F}_{\mathrm{st}}\right.$ and $\left.\mathrm{G}_{\mathrm{st}}\right)$, gene flow $\left(\mathrm{N}_{\mathrm{m}}\right)$ $\left[\mathrm{N}_{\mathrm{m}}=0.25\left(1-\mathrm{F}_{\mathrm{st}}\right) / \mathrm{F}_{\mathrm{st}}\right]$, percentage of polymorphic loci (PPL), observed number of alleles $\left(\mathrm{N}_{\mathrm{a}}\right)$, effective number of alleles $\left(\mathrm{N}_{\mathrm{e}}\right)$ and Shannon's information index (I). The polymorphism information content (PIC) was calculated by the formula:

$\mathrm{PIC}=1-\sum_{i=1}^{n} P_{i}^{2}-\sum_{i=1}^{n-1} \sum_{j=i+1}^{n} 2 P_{i}^{2} P_{j}^{2}$

where $P_{i}$ and $P_{j}$ are the frequencies of the $i_{\text {th }}$ and $j_{\text {th }}$ allele, and $\mathrm{n}$ is the number of alleles (Botstein et al. 1980). The genetic relationship of Phaonia species from the studied ten regions of China was also analyzed using POPGENE version 1.32.

A clustering analysis was used to generate a dendrogram for 46 accessions using the unweighted pair-group method with arithmetic mean (UPGMA) and Nei's unbiased genetic distance using the NTSYPC 2.10 software package (Nei 1978). A Mantel test was used to examine the relationship between UPGMA results and the co-characterization correlation of the genetic distance matrix.

\section{Results}

\subsection{EST-SSR marker polymorphisms}

A total of 216 EST-SSR markers were developed, and after screening three times there were 18 markers which produced polymorphic, stable and clear bands, which were used in the further study (Table 2). The dominant motifs among the 18 EST-SSR markers of the studied Muscidae species were the trinucleotides and the dinucleotides. The different frequencies were 20.7, 74.0, 4.6, 0.3, 0.3 and $0.1 \%$ for the di-, tri-, tetra-, penta-, hexa-, and other dinucleotides, respectively. In the trinucleotides, the motifs AAG, AAC, ACC, AGC, ACG had a high frequency whereas in the dinucleotides that was the case with the motifs AT and AC.

The 18 screened EST-SSR markers of the species of ten genera (Table 2) produced a total of 216 alleles, with an average of 6.1 alleles per locus. The PIC value provides an estimate of the discriminatory power of a locus by taking in account the number of alleles, which are expressed, and the relative frequencies of these alleles. In general, PIC values have been used to evaluate the polymorphism information content of each marker. Following Botstein et al. (1980) the following scale was used: $\mathrm{PIC}>0.5$ with high polymorphism information, $0.5 \geq \mathrm{PIC} \geq 0.25$ moderate, $\mathrm{PIC}<0.25$ low. In this study, the PIC values of the 18 EST-SSR markers ranged from 0.642 to 0.908 , with the mean of 0.860 (Table 2), which showed high polymorphism (Angus et al. 2011). The values of effective number of alleles $\left(\mathrm{N}_{\mathrm{e}}\right)$ ranged from 3.267 to 11.765 , with the mean of 8.720 . The degree of heterozygosity $\left(\mathrm{H}_{\mathrm{e}}\right)$ reflected the consistency of population genotype; however, the $\mathrm{H}_{\mathrm{o}}$ value $(0.547)$ was slightly lower than $\mathrm{H}_{\mathrm{e}}$ value $(0.878)$ per locus for the ten genera. The values of Shannon's information index (I) ranged from 1.323 to 2.586 , with the mean of 2.259 , which showed high polymorphism as well. 
Table 2. The sequence $\left(5^{\prime} \rightarrow 3^{\prime}\right)$ ( $F$ : forward, R: reverse), annealing temperature $\left(T_{m}\right)$, repeat motif and expected product size (bp) of 18 polymorphic EST-SSR markers and their diversity statistic values ${ }^{s}$ in Muscidae of ten regions in China.

\begin{tabular}{llllllllllllll}
\hline Marker & $\mathrm{T}_{\mathrm{m}}\left({ }^{\circ} \mathrm{C}\right)$ & motif & bp & $\mathrm{N}_{\mathrm{a}}$ & $\mathrm{N}_{\mathrm{e}}$ & $\mathrm{H}_{\mathrm{o}}$ & $\mathrm{H}_{\mathrm{e}}$ & $\mathrm{l}$ & $\mathrm{F}_{\mathrm{st}}$ & $\mathrm{N}_{\mathrm{m}}$ & PIC
\end{tabular}

MD108, F: CTTTGTTGCTCAGTTGGGGT, R: AAACATTTGTTTTGGGCCTG

$\begin{array}{lllllllllll}60 & (\mathrm{AGC})_{6} & 252 & 10 & 6.274 & 0.551 & 0.845 & 2.264 & 0.158 & 1.332 & 0.821\end{array}$

MD110, F: TGTGCGCTACGTTTGAAGAC, R: ATTTTGATGCAGATGAGCCC

$\begin{array}{lllllllllll}60 & (\mathrm{AT})_{9} & 213 & 9 & 4.961 & 0.573 & 0.803 & 1.806 & 0.217 & 0.902 & 0.770\end{array}$

MD115, F: CCCATAAAGGGCTGAAAAGA, R: AAAATATCATTACAATCGTCACCA

$\begin{array}{lllllllllll}58 & (\mathrm{AG})_{6} & 270 & 11 & 9.195 & 0.564 & 0.896 & 0.292 & 0.214 & 0.921 & 0.881\end{array}$

MD123, F: GGGATCTGATGCAATACGGT, R: TCATCAATTTCATTGGCTGC

$\begin{array}{lllllllllll}59 & (\mathrm{AAG})_{5} & 251 & 13 & 9.985 & 0.502 & 0.904 & 2.414 & 0.190 & 1.066 & 0.891\end{array}$

MD136, F: GAAAGCGAGATGGCAAGAAC, R: CCCGGCACTGTTGTTAAAGT

$\begin{array}{lllllllllll}60 & (\mathrm{GGT})_{5} & 278 & 12 & 7.675 & 0.523 & 0.874 & 2.227 & 0.278 & 0.649 & 0.857\end{array}$

MD148, F: AACCAAAAACAAAATGGGGA, R: GCATGACGCATGACTTTTCT

$\begin{array}{lllllllllll}59 & (\mathrm{AAT})_{5} & 234 & 14 & 11.338 & 0.557 & 0.916 & 2.519 & 0.196 & 1.026 & 0.904\end{array}$

MD150, F: AAAAGGGAGCTGGAACAGGT, R: GCTCCAGCAAGAACAGGAAG

$\begin{array}{lllllllllll}60 & (\mathrm{ATT})_{5} & 259 & 14 & 10.040 & 0.554 & 0.905 & 2.464 & 0.330 & 0.508 & 0.892\end{array}$

MD157, F: ACCAGCCACCATTTATAGCG, R: CGGGTCGTAGGTGAAATGTT

$\begin{array}{lllllllllll}59 & (\mathrm{CAA})_{5} & 217 & 14 & 11.109 & 0.552 & 0.917 & 2.535 & 0.226 & 0.856 & 0.905\end{array}$

MD158, F: CACAACCCTTGAAAAGTCGC, R: CAAGACGAGGTGGAGATGGT

$\begin{array}{lllllllllll}60 & (\mathrm{AGT})_{5} & 277 & 14 & 11.547 & 0.562 & 0.918 & 2.530 & 0.185 & 1.101 & 0.906\end{array}$

MD168, F: AGTTTGACGGCGAAAATGAG, R: CTGCGGTGCTGACAATAGAA

$\begin{array}{lllllllllll}60 & (\mathrm{GA})_{7} & 256 & 14 & 10.565 & 0.534 & 0.910 & 2.473 & 0.294 & 0.600 & 0.897\end{array}$

MD171, F: AGTTTGACGGCGAAAATGAG, R: CTGCGGTGCTGACAATAGAA

$\begin{array}{lllllllllll}60 & (\mathrm{GA})_{10} & 262 & 14 & 12.610 & 0.597 & 0.925 & 2.586 & 0.121 & 1.816 & 0.915\end{array}$

MD174, F: TTAATTGCGGACCCAATAGC, R: ATCAAAGTTGCGTCCAGGTC

$\begin{array}{lllllllllll}60 & (\mathrm{AAC})_{8} & 281 & 14 & 11.765 & 0.553 & 0.920 & 2.537 & 0.242 & 0.783 & 0.908\end{array}$

MD185, F: ATTCCCCTCCCTCCCTAAAT, R: ATGGTTGACCCAAACCGTAA

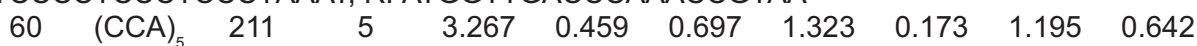

MD187, F: AGCTGCAACAGCCCTTAAAA, R: CACGCCACTTTACACCACAC

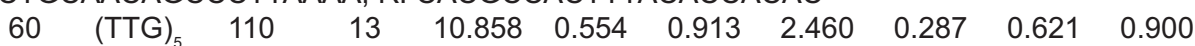

MD191, F: TGCATTTGCTTTATGGACTGAC, R: TGGCCAGTCATTACTTTTGG

$\begin{array}{lllllllllll}60 & (\mathrm{TA})_{12} & 244 & 14 & 11.541 & 0.557 & 0.918 & 2.540 & 0.105 & 2.131 & 0.906\end{array}$

MD195, F: CAACCGCTCAGTGGATACCT, R: TTGGCTTTGGAGGAAAGAAA

$\begin{array}{lllllllllll}59 & (A C A)_{6} & 206 & 13 & 10.633 & 0.544 & 0.911 & 2.465 & 0.188 & 1.080 & 0.898\end{array}$

MD198, F: GCAACTACAAACAGCAACGC, R: ACCAGACGACCAAATGGAAG

$\begin{array}{lllllllllll}59 & (\mathrm{GCA})_{5} & 270 & 12 & 6.412 & 0.548 & 0.848 & 2.122 & 0.199 & 1.006 & 0.827\end{array}$

MD199, F: GTCGAACCACTCAGGGACAC, R: GAAGCCCTTTTTGTCAGCAG

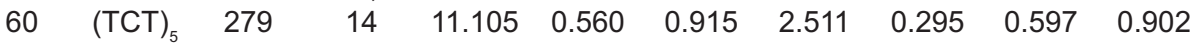

\begin{tabular}{lllllllllll}
\hline Mean & 59 & 223 & 12 & 8.720 & 0.547 & 0.878 & 2.259 & 0.238 & 0.842 & 0.860
\end{tabular}

\$) $\mathrm{N}_{\mathrm{a}}$ : observed number of alleles, $\mathrm{N}_{\mathrm{e}}$ : effective number of alleles, $\mathrm{H}_{\mathrm{o}}$ : observed heterozygosity, $\mathrm{H}_{\mathrm{e}}$ : expected heterozygosity, I: Shannon's information index, $\mathrm{F}_{\mathrm{st}}$ : coefficient of genetic differentiation, $\mathrm{N}_{\mathrm{m}}$ : gene flow, PIC: polymorphism information content.

\subsection{Genetic diversity of genera}

The mean value of the percentage of polymorphic loci (PPL) of Phaonia species from the ten regions in China was $85.4 \%$ (range: $71.4-100 \%$,
Table 3). The Neimenggu (NC) and Jinlin (JC) regions showed the highest PPL (100\%), followed by Sichuan (SE) and Qinghai (QK), while for Xinjiang (XT) it was the lowest (71.4\%, Table 3). The mean value of PIC of the ten genera was 
Table 3. Genetic diversity in natural populations of Phaonia species from ten regions in China.

\begin{tabular}{|c|c|c|c|c|c|}
\hline $\begin{array}{l}\text { Popu- } \\
\text { lation }^{b}\end{array}$ & $\begin{array}{l}\text { No. of } \\
\text { Alleles }\end{array}$ & I & $\mathrm{H}_{\mathrm{o}}$ & PPL\% & PIC \\
\hline XT & 7 & 1.384 & 0.511 & 71.4 & 0.710 \\
\hline $\mathrm{XN}$ & 12 & 1.614 & 0.612 & 83.3 & 0.989 \\
\hline QK & 9 & 1.489 & 0.784 & 90.5 & 0.793 \\
\hline YY & 8 & 1.397 & 0.658 & 77.8 & 0.910 \\
\hline SE & 14 & 1.809 & 0.690 & 92.9 & 0.924 \\
\hline HW & 4 & 1.124 & 0.524 & 75.0 & 0.627 \\
\hline ST & 6 & 1.320 & 0.483 & 83.3 & 0.511 \\
\hline $\mathrm{NC}$ & 3 & 1.001 & 0.582 & 100 & 0.571 \\
\hline LQ & 10 & 1.499 & 0.691 & 80.0 & 0.729 \\
\hline JC & 5 & 1.279 & 0.625 & 100 & 0.876 \\
\hline Mean & 8.3 & 1.391 & 0.672 & 85.4 & 0.764 \\
\hline
\end{tabular}

a) I: Shannon's information index, $\mathrm{H}_{0}$ : observed heterozygosity, PPL\%: percentage of polymorphic loci, PIC: polymorphism information content.

b) For abbreviations of populations, see Table 1 .

0.764 (range: 0.511-0.989), the Xizang (XN) species assemblage having the highest PIC value (0.989), and the Shanxi (ST) species assemblage the lowest one (0.511). The Sichuan (SE) species assemblage had the highest value of the Shannon's information index $(\mathrm{I}=1.809)$, and the Neimenggu (NC) species assemblage the lowest one (1.168). The mean value of the Shannon's information index of the ten genera was 1.391. The observed heterozygosity $\left(\mathrm{H}_{\mathrm{o}}\right)$ value ranged from
0.511 to 0.784 . The values of $\mathrm{H}_{\mathrm{o}}$ and PIC of Qinghai (QK), Liaoning (LQ), Sichuan (SE) and Yunnan (YY) genera were relatively high. Accordingly, the genera in Western China had a high genetic diversity, closely followed by the northeast regions.

Based on the UPGMA Dendrogram, the Phaonia genus can be divided into two main branches, the Xinjiang (XT), Hainan (HW), Shanxi (ST), Liaoning (LQ), Neimenggu (NC) and Jinlin (JC) assemblages in northeast part of China clustering into the other branch (Fig. 2, Table 4). The LQ and NC assemblages had a close relationship within this branch, followed by HW and ST, but XT had a larger genetic distance from others. The western regions, Qinghai $(\mathrm{XN})$, Yunnan (YY), Qinghai (QK) and Sichuan (SE), clustered into another branch. XN and YY had a closer relationship within it than the other two (QK and SE).

Nei's (1978) genetic distances among the ten genera of Muscidae were also calculated. The resulting UPGMA dendrogram is shown in Fig. 3. The species of most genera cluster in the branch of their own, except Lispe from Xinjiang (XT) clustered with species of Brontaea. The degree of congruence of UPGMA results and the Mantel test of co-characterization correlation of genetic distance matrix was excellent with its co-phenetic correlation (r) value being 0.876 .
Fig. 2. UPGMA dendrogram of Phaonia species among ten regions in China (Table 1).

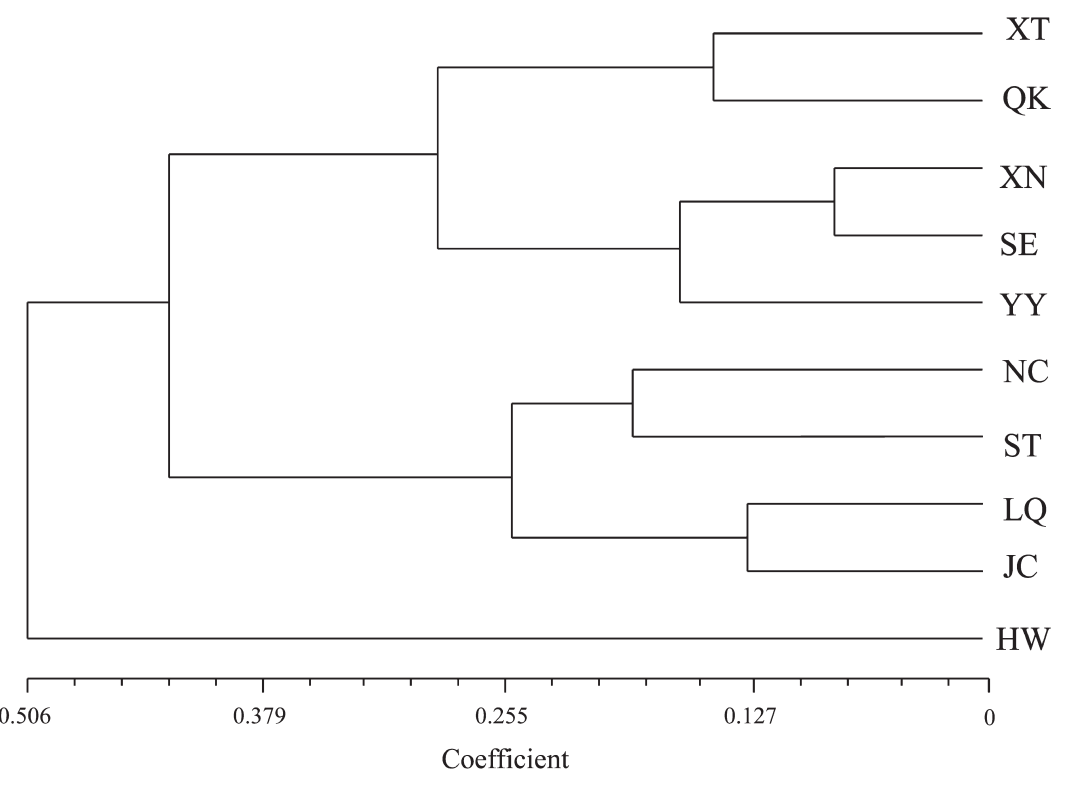


Table 4. Nei's genetic identity (above diagonal) and genetic distance (below diagonal) for Phaonia species from ten regions of China (for abbreviations of the regions, see Table 1).

\begin{tabular}{lcccccccccc}
\hline Region & $\mathrm{XT}$ & $\mathrm{XN}$ & $\mathrm{QK}$ & $\mathrm{YY}$ & $\mathrm{SE}$ & $\mathrm{HW}$ & $\mathrm{SE}$ & $\mathrm{NC}$ & $\mathrm{LQ}$ & $\mathrm{JC}$ \\
\hline $\mathrm{XT}$ & $* * * * *$ & 0.8383 & 0.8302 & 0.8214 & 0.7616 & 0.8034 & 0.8392 & 0.8326 & 0.8755 & 0.8192 \\
$\mathrm{XN}$ & 0.1764 & ${ }^{* * * *}$ & 0.8528 & 0.8748 & 0.8224 & 0.7503 & 0.7826 & 0.8030 & 0.7833 & 0.7863 \\
$\mathrm{QK}$ & 0.1861 & 0.1593 & $* * * * *$ & 0.8464 & 0.8420 & 0.7644 & 0.7952 & 0.7958 & 0.8069 & 0.7843 \\
YY & 0.1968 & 0.1338 & 0.1667 & $* * * * *$ & 0.8531 & 0.8041 & 0.8345 & 0.8029 & 0.7976 & 0.7602 \\
SE & 0.2723 & 0.1955 & 0.1720 & 0.1589 & $* * * * *$ & 0.7655 & 0.8101 & 0.7659 & 0.7805 & 0.7059 \\
HW & 0.2190 & 0.2873 & 0.2687 & 0.2181 & 0.2673 & $* * * *$ & 0.9320 & 0.8872 & 0.8973 & 0.8389 \\
ST & 0.1753 & 0.2451 & 0.2291 & 0.1809 & 0.2106 & 0.0704 & $* * * * *$ & 0.9193 & 0.9403 & 0.8793 \\
NC & 0.1832 & 0.2194 & 0.2285 & 0.2195 & 0.2667 & 0.1197 & 0.0841 & $* * * * *$ & 0.9201 & 0.9235 \\
LQ & 0.1330 & 0.2442 & 0.2146 & 0.2262 & 0.2478 & 0.1083 & 0.0615 & 0.0832 & $* * * * *$ & 0.8884 \\
JC & 0.1994 & 0.2404 & 0.2430 & 0.2742 & 0.3483 & 0.1756 & 0.1287 & 0.0796 & 0.1183 & $* * * * *$ \\
\end{tabular}

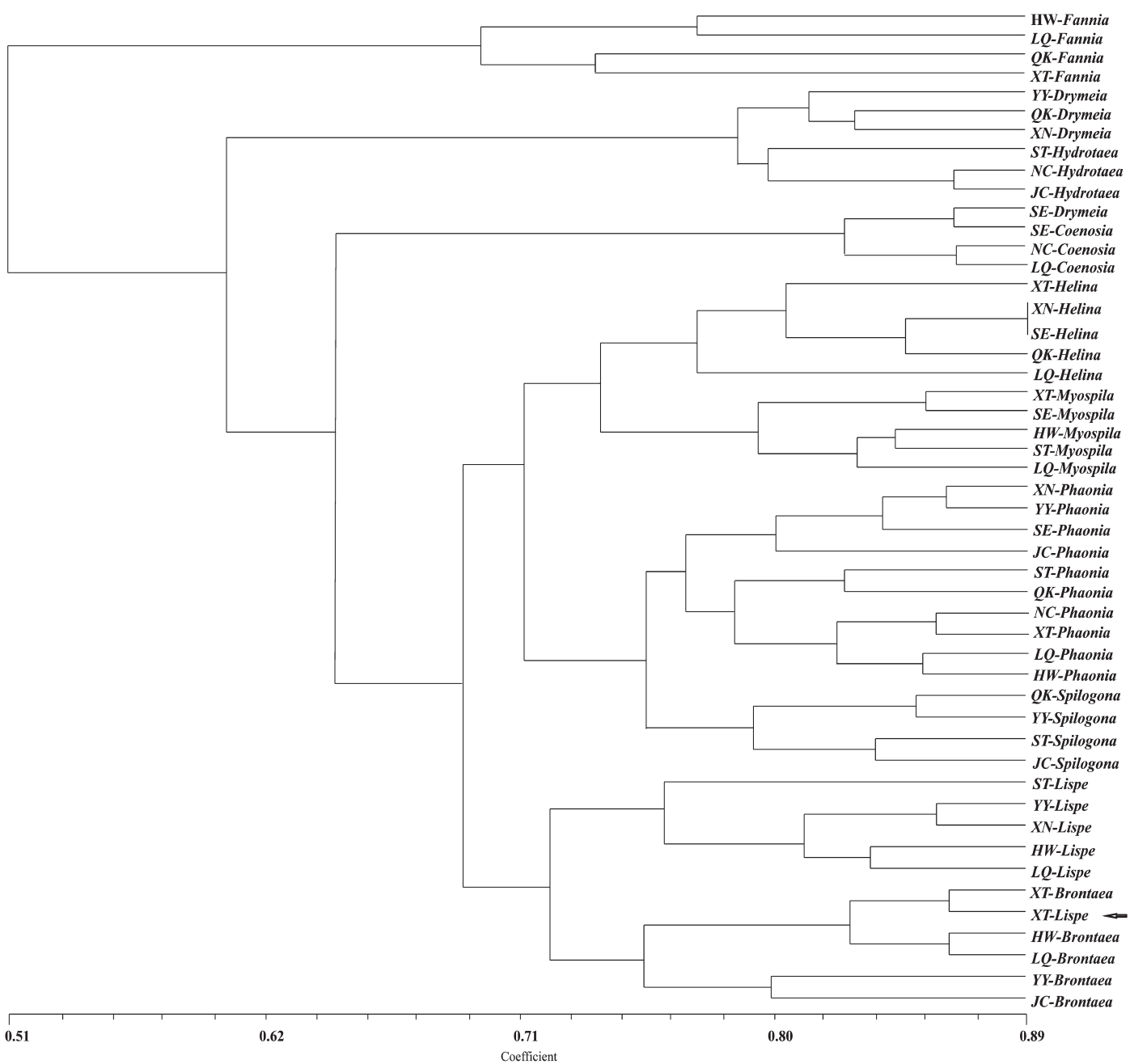

Fig. 3. Dendrogram of 46 species assmblages of Muscidae of ten regions in China (Table 1) based on EST-SSR data (UPGMA). The single Lispe in the Brontaea branch has been indicated by an arrow. 
The species and the number of them in each region were different and the genetic differentiation coefficient $\left(\mathrm{F}_{\mathrm{st}}\right)$ was also different. The mean $\mathrm{F}_{\text {st }}$ value of the 18 loci for the ten species assemblages was 0.238 . The mean value of gene flow $\left(\mathrm{N}_{\mathrm{m}}\right)$ was 0.842 , when the EST-SSR molecular markers were used to detect the genetic differentiation of the studied Muscidae species. The mean $\mathrm{F}_{\text {st }}$ value of the 36 EST-SSR molecular markers for the ten species assemblages was relatively high, 0.238 . This is consistent with the generally low values of gene flow (mean $\mathrm{N}_{\mathrm{m}}=0.842$ ). However, the low $\mathrm{F}_{\mathrm{st}}(0.121)$ and the high $\mathrm{N}_{\mathrm{m}}(1.816)$ (Table 2) values also existed, showing low differentiation in some markers.

\section{Discussion}

Transferability of the chosen 18 EST-SSR markers was examined for ten different species assemblages, which successfully amplified stable and clear bands. Generally, successful cross-genera amplification of the EST-SSRs usually occurs in the related species within a genus, but a high cross-genera amplification demonstrated for the EST-SSR markers developed in this study demonstrate a high transferability being applicable to ten different species assemblages, thus being potentially useful in comparative genomics. To conclude, in this study, we developed and characterized 18 new EST-SSR markers for Muscidae species aiming to enrich the set of SSR markers for this fly family. Most of the markers were polymorphic, i.e. more than one allele could be detected in the set of ten assemblage's species. Accordingly, the results demonstrated that these markers are applicable in the surveyed species assemblages and potentially in other Muscidae species, too.

In addition, the markers developed in this study for the research of genetic diversity of Phaonia species revealed that these Phaonia species had high genetic diversity and displayed genetic differentiation of natural species assemblages. The genetic diversity of the western regions in China, namely Xizang (XN), Sichuan (SE) and Yunnan (YY), was generally higher (PIC 0.900) than in Shanxi (ST) (PIC=0.511).

Muscidae flies are major pest species and are thus economically important. In China, previous studies on flies have been about the morphology and biology, while only few have reported about molecular biology, especially molecular markers. The development and improvement of informative molecular markers will further expand and deepen the knowledge on genetic diversity of Muscidae.

Acknowledgements. This study was supported by the National Nature Science Foundation of China (No. 31370400), the Youth Foundation Project of Eastern Liaoning University (No. 2015QN006) and Dandong scientific research project: Gene mapping and variety identification technology of Actinidia arguta in Dandong. Special thanks to Dr. A. C. Pont (Oxford University Museum of Natural History, Oxford, UK) for comments on and improving the manuscript and thanks also to Xiaoxia-Cai and Dingquan-Wang for their help.

\section{References}

Angus, R. B., Dellow, J., Winder, C. \& Credland, P. F. 2011: Karyotype differences among four species of Callosobruchus Pic (Coleoptera: Bruchidae). — Journal of Stored Products Research 47(2): 76-81.

Botstein, D., White, R. L., Skolnick, M. \& Davis, R. W. 1980: Construction of a genetic linkage map in man using restriction fragment length polymorphisms. American Journal of Human Genetics 32(3): 314 331.

Carvalho, C. J. B. de, Couri, M. S., Pont, A. C., Pamplona, D. \& Lopes, S. M. 2002: A catalogue of the Muscidae (Diptera) of the Neotropical Region. - Zootaxa 860: $1-282$.

Chen, X. M. 2009: The morphology, biology and genetic differentiation research of Musca domestica in different geographic populations. - Huazhong Agricultural University 1: 68-73. [In Chinese.]

Evenhuis, N. L., Pape, T., Pont, A. C. \& Thompson, F. C. 2010: Flying after Linnaeus: Diptera names since Systema Naturae (1758). — In: Polaszek, A. (ed.), Systema Naturae 250: 75-82, The Linnaean Ark. CRC Press. 321 pp.

Hennig, W. 1955-1964: Family Muscidae. — In: Lindner, E. (ed.), Die Fliegen der Palaearktischen Region, 63b. Schweizerbart, Stuttgart. 1110 pp.

Kutty, S. N., Pape, T., Pont, A., Wiegmann, B. M. \& Meier, R. 2008: The Muscoidea (Diptera: Calyptratae) are paraphyletic: evidence from four mitochondrial and four nuclear genes. - Molecular Phylogenetics and Evolution 49: 639-652.

McAlpine J. F. 1981: Morphology and terminology adults. - In: McAlpine, J. F., Peterson, B. V., Shewell, G. E., Teskey, H. J., Vockeroth, J. R. \& Wood, D. M. 
(eds), Manual of Nearctic Diptera. Volume 1. - Agriculture Canada. Monograph 27: 9-63.

Michelsen, V. 2000: Oldest authentic record of a fossil calyptrate flies (Diptera): a species of Anthomyiidae from early Coenozoic Baltic amber. - Studia Dipterologica 7: 11-18.

Nei, M. 1978: Estimation of average heterozygosity and genetic distance from a small number of individuals. - Genetics 89: 583-590.

Posada, D. 2008: JModel Test: phylogenetic model averaging. - Molecular Biology Evolution 25: 1253 1256.

Renaud, A., Savage, J. \& Adamowicz, S. 2012: DNA barcoding of Northern Nearctic Muscidae (Diptera) re- veals high correspondence between morphological and molecular species limits. - BMC Ecology 12: 24-38.

Savage, J. \& Wheeler, T. A. 2004: Phylogeny of the Azeliini (Diptera: Muscidae). — Studia Dipterologica 11: 259-299.

Schuehli, G. S., Carvalho, C. J. B. de \& Wiegmann, B. M. 2007: Molecular phylogenetics of the Muscidae (Diptera: Calyptratae): New ideas in a congruence context. - Invertebrate Systematics 21(3): 263-278.

Xue, W. Q., Zhang, C. T., Wang, M. F. \& Zhou, Z. K. 1992: Study on the genus Drymeia of China (Diptera: Muscidae). - A paper for the $19^{\text {th }}$ international congress of Entomology, Shenyang Normal University. 16 pp. 